OPEN ACCESS

Edited by:

Sandra Torriani,

University of Verona, Italy

Reviewed by:

Beatriz Martínez,

Consejo Superior de Investigaciones

Cientificas (CSIC), Spain

Daniel M. Linares,

Teagasc-The Irish Agriculture and Food Development Authority, Ireland

*Correspondence: Helge Holo

helge.holo@nmbu.no

Specialty section:

This article was submitted to

Food Microbiology,

a section of the journal

Frontiers in Microbiology

Received: 17 November 2016

Accepted: 18 January 2017

Published: 03 February 2017

Citation:

Frantzen CA, Kot W, Pedersen TB, Ardö YM, Broadbent JR, Neve $H$, Hansen LH, Dal Bello F, Østlie HM,

Kleppen HP, Vogensen FK and Holo $H$ (2017) Genomic Characterization of

Dairy Associated Leuconostoc

Species and Diversity of

Leuconostocs in Undefined Mixed

Mesophilic Starter Cultures.

Front. Microbiol. 8:132.

doi: 10.3389/fmicb.2017.00132

\section{Genomic Characterization of Dairy Associated Leuconostoc Species and Diversity of Leuconostocs in Undefined Mixed Mesophilic Starter Cultures}

Cyril A. Frantzen ${ }^{1}$, Witold Kot ${ }^{2}$, Thomas B. Pedersen ${ }^{3}$, Ylva M. Ardö ${ }^{3}$, Jeff R. Broadbent ${ }^{4}$, Horst Neve ${ }^{5}$, Lars H. Hansen ${ }^{2}$, Fabio Dal Bello ${ }^{6}$, Hilde M. Ostlie ${ }^{1}$, Hans P. Kleppen ${ }^{1,7}$, Finn K. Vogensen ${ }^{3}$ and Helge Holo ${ }^{1,8 *}$

1 Laboratory of Microbial Gene Technology and Food Microbiology, Department of Chemistry, Biotechnology and Food Science, Norwegian University of Life Sciences, Ås, Norway, ${ }^{2}$ Department of Environmental Science, Aarhus University, Roskilde, Denmark, ${ }^{3}$ Department of Food Science, University of Copenhagen, Copenhagen, Denmark, ${ }^{4}$ Department of Nutrition, Dietetics and Food Sciences, Utah State University, Logan, UT, USA, ${ }^{5}$ Department of Microbiology and Biotechnology, Max Rubner-Institut, Kiel, Germany, ${ }^{6}$ Sacco Srl, Cordorago, Italy, ${ }^{7}$ ACD Pharmaceuticals AS, Leknes, Norway, ${ }^{8}$ TINE SA, Oslo, Norway

Undefined mesophilic mixed (DL-type) starter cultures are composed of predominantly Lactococcus lactis subspecies and 1-10\% Leuconostoc spp. The composition of the Leuconostoc population in the starter culture ultimately affects the characteristics and the quality of the final product. The scientific basis for the taxonomy of dairy relevant leuconostocs can be traced back 50 years, and no documentation on the genomic diversity of leuconostocs in starter cultures exists. We present data on the Leuconostoc population in five DL-type starter cultures commonly used by the dairy industry. The analyses were performed using traditional cultivation methods, and further augmented by next-generation DNA sequencing methods. Bacterial counts for starter cultures cultivated on two different media, MRS and MPCA, revealed large differences in the relative abundance of leuconostocs. Most of the leuconostocs in two of the starter cultures were unable to grow on MRS, emphasizing the limitations of culture-based methods and the importance of careful media selection or use of culture independent methods. Pan-genomic analysis of 59 Leuconostoc genomes enabled differentiation into twelve robust lineages. The genomic analyses show that the dairy-associated leuconostocs are highly adapted to their environment, characterized by the acquisition of genotype traits, such as the ability to metabolize citrate. In particular, Leuconostoc mesenteroides subsp. cremoris display telltale signs of a degenerative evolution, likely resulting from a long period of growth in milk in association with lactococci. Great differences in the metabolic potential between Leuconostoc species and subspecies were revealed. Using targeted amplicon sequencing, the composition of the Leuconostoc population in the five commercial starter cultures was shown to be significantly different. Three of the cultures were dominated by Ln. mesenteroides subspecies cremoris. Leuconostoc pseudomesenteroides dominated in two of the 
cultures while Leuconostoc lactis, reported to be a major constituent in fermented dairy products, was only present in low amounts in one of the cultures. This is the first in-depth study of Leuconostoc genomics and diversity in dairy starter cultures. The results and the techniques presented may be of great value for the dairy industry.

Keywords: dairy, cheese, leuconostoc, comparative, genomics, diversity analysis, starter cultures, differentiation

\section{INTRODUCTION}

Mesophilic mixed (DL-type) starter cultures used in the production of Dutch-type cheeses are composed of undefined mixtures of homofermentative Lactococcus lactis subsp. lactis (Lc. lactis), Lactococcus lactis subsp. cremoris (Lc. cremoris), Lactococcus lactis subsp. lactis biovar. diacetylactis (Lc. diacetylactis) and heterofermentative Leuconostoc spp. The latter two provide aroma and texture by metabolizing citrate, producing diacetyl, acetoin and $\mathrm{CO}_{2}$, while Lc. cremoris and Lc. lactis are the major acid producers through fermentation of lactose. In many cheeses, diacetyl is an important aroma compound, and $\mathrm{CO}_{2}$ is important for the eye formation (Hugenholtz, 1993). In fermented dairy products, Leuconostoc grows in association with the acid-producing lactococci and have been suggested to play a role in promoting the growth of citrate positive Lactococcus strains (Vedamuthu, 1994; Bandell et al., 1998; Hache et al., 1999). The importance of Leuconostoc in cheese production is widely recognized. DL-type starter cultures are predominantly Lactococcus spp., Leuconostoc spp. commonly accounting for 1-10\% of the starter culture population (Cogan and Jordan, 1994). However, knowledge on the species diversity of Leuconostoc included in these starter cultures, or the composition of Leuconostoc through the culture production is sparse. Due to the low initial number and relatively weak ability to ferment lactose, Leuconostoc spp. are not believed to have a significant effect in the acidification process in the early stages of cheese making (Ardö and Varming, 2010). However, leuconostocs have been shown to dominate the cheese microbiota in the later stages of ripening with added propionic acid bacteria (Porcellato et al., 2013; Østlie et al., 2016). The genus Leuconostoc is comprised of 13 species, with the species Leuconostoc mesenteroides divided into subspecies mesenteroides, dextranicum, cremoris, and suionicum (Hemme and Foucaud-Scheunemann, 2004; $\mathrm{Gu}$ et al., 2012). The Leuconostoc species (or subspecies) relevant for dairy production are Leuconostoc mesenteroides subsp. mesenteroides (Ln. mesenteroides), Leuconostoc mesenteroides subsp. dextranicum ( $\mathrm{Ln}$. dextranicum), Leuconostoc mesenteroides subsp. cremoris (Ln. cremoris), Leuconostoc pseudomesenteroides (Ln. pseudomesenteroides) and Leuconostoc lactis (Ln. lactis) (Cogan and Jordan, 1994; Thunell, 1995)

The bases for Leuconostoc taxonomy are results from cultivation-dependent methods, followed by phenotypic/biochemical characterization or non-specific molecular methods. In addition to being tedious and timeconsuming, classical cultivation-dependent methods are known to underestimate the number of Leuconostoc spp., especially
Ln. cremoris (Vogensen et al., 1987; Ward et al., 1990; Auty et al., 2001). In addition, concerns on the lack of stability and reproducibility of phenotypical methods have been raised (Thunell, 1995; Barrangou et al., 2002). Several molecular typing methods, such as RAPD, PFGE, RFLP, Rep-PCR, MLST, MALDI-TOF MS, plasmid profiling and 16S rRNA targeted differentiation have been employed to characterize or identify Leuconostoc isolates (Villani et al., 1997; Björkroth et al., 2000; Cibik et al., 2000; Pérez et al., 2002; Sánchez et al., 2005; Vihavainen and Björkroth, 2009; Nieto-Arribas et al., 2010; Alegria et al., 2013; Zeller-Péronnet et al., 2013; Dan et al., 2014; Zhang et al., 2015). However, most of these techniques requiring a preliminary stage of cultivation and comparison of results between the methods and between different laboratories remains challenging. Often, these methods were developed to work with only one or two species of Leuconostoc, so they do not provide subspecies differentiation, yield inconclusive results, yield results that are hard to reproduce, or provide arbitrary differentiation of isolates not sufficiently tethered to phenotypic traits. So far, the work by Dr. Ellen Garvie on the growth and metabolism of Leuconostoc spp. (Garvie, 1960, 1967, 1969, 1979, 1983; Garvie et al., 1974), and DNA-DNA hybridization studies (Farrow et al., 1989) remains the basis for the taxonomical division of dairy relevant leuconostocs.

The Leuconostoc genus has also not been subject to extensive genomic research, and information on the genomic diversity or species population dynamics through the cheese production processes is scarce if available at all. Scientific literature and product information on starter cultures pre-dating the genomic age list Ln. cremoris and Ln. lactis as the key Leuconostoc in undefined mixed mesophilic starter cultures (Lodics and Steenson, 1990; Johansen and Kibenich, 1992; Vedamuthu, 1994). However, in recent years, isolation of Ln. mesenteroides, $L n$. dextranicum, and Ln. pseudomesenteroides is more common from starter cultures or from cheese derivatives (Olsen et al., 2007; Kleppen et al., 2012; Pedersen et al., 2014a,b; Østlie et al., 2016).

Here we present genomic comparative analysis of Leuconostoc spp. and present data on the diversity and composition of Leuconostoc populations in five commercially available DLtype starter cultures. Using traditional cultivation methods in combination with high-throughput sequencing techniques, we provide robust species and subspecies differentiation, and direct population composition analysis using targeted ampliconsequencing techniques. To our knowledge, this is the first indepth genomic work performed on the Leuconostoc genus, and the first data published on Leuconostoc diversity in DL-type starter cultures. 


\section{MATERIALS AND METHODS}

\section{Cultivation of Bacterial Strains and Starter Cultures}

All bacterial strains used in this study are listed in Supplementary Table S1. The two different media used for cultivation were de Man Rogosa Sharpe (MRS) (Difco, Detroit, Michigan, USA), and modified PCA (MPCA). PCA (Sigma-Aldrich, Oslo, Norway) was supplemented with $0.5 \mathrm{~g} / \mathrm{L}$ Tween $80,5.0 \mathrm{~g} / \mathrm{L}$ ammoniumcitrate, $1 \mathrm{~g} / \mathrm{L}$ skim milk powder (TINE SA, Oslo, Norway), $0.04 \mathrm{~g} / \mathrm{L} \mathrm{FeSO}{ }_{4}, 0.2 \mathrm{~g} / \mathrm{L} \mathrm{MgSO}_{4}, 0.05 \mathrm{~g} / \mathrm{L} \mathrm{MnSO}_{4}$, and 10.0 $\mathrm{g} / \mathrm{L}$ glucose. Glucose was sterile filtered separately and added after autoclaving. Both media were supplemented with $40 \mu \mathrm{g} / \mathrm{mL}$ vancomycin to select for Leuconostoc. Three separate extractions from one batch of each starter cultures (A, B, C, D, and E) were suspended in MPCA to an optical density at $600 \mathrm{~nm}\left(\mathrm{OD}_{600}\right)$ of 1.0 , serially diluted in $10 \%(\mathrm{w} / \mathrm{v})$ skim milk and spread plated on MRS and MPCA agar plates in triplicate. The plates were incubated at $22^{\circ} \mathrm{C}$ for 5 days before colony enumeration. Isolates were transferred to MRS and MPCA broth media, respectively, and cultivated at $22^{\circ} \mathrm{C}$ for two passages before aliquots were supplemented with $15 \%(\mathrm{w} / \mathrm{v})$ glycerol (Sigma-Aldrich) and stored at $-70^{\circ} \mathrm{C}$.

\section{Genome Sequencing, Assembly, and Annotation}

Genomic DNA from Leuconostoc isolates was extracted from 1 $\mathrm{mL}$ of overnight culture using Qiagen DNeasy Blood \& Tissue Kit (Qiagen, Hilden, Germany). The cells were lysed with 40 $\mathrm{mg} / \mathrm{mL}$ lysozyme (Qiagen, Hilden, Germany) and bead-beating in a FastPrep ${ }^{\circledR}-24$ (MP Biomedicals, Santa Ana, California) using $0.5 \mathrm{~g}$ acid-washed beads $(<106 \mu \mathrm{m})$ (Sigma-Aldrich) prior to column purification. DNA libraries were made using the Nextera XT DNA Sample Prep kit (Illumina, San Diego, California, USA) according to manufacturer instructions and sequenced with Illumina MiSeq (Illumina, San Diego, California, USA) using V3 chemistry for 33 isolates sequenced at the Norwegian University of Life Sciences, and V2 chemistry for 13 isolates sequenced at the Aarhus University. Raw sequences were adapter trimmed, quality filtered ( $\mathrm{Q}>20$ ), de novo assembled using SPAdes V3.7.1 (Nurk et al., 2013) and annotated using the Prokka pipeline (Seemann, 2014). Contigs shorter than 1000 bp or with $<5$ times coverage were removed from each assembly prior to gene annotation. Thirteen publicly available genomes of Leuconostoc obtained from the National Center for Biotechnology Information (NCBI) database were also included in the dataset (Jung et al., 2012; Meslier et al., 2012; Erkus et al., 2013; Pedersen et al., 2014a,b; Campedelli et al., 2015; Østlie et al., 2016). This whole genome project has been deposited at DDBJ/ENA/GenBank under the BioProject PRJNA352459.

\section{Genomic Analysis}

The protein coding sequences of all Leuconostoc isolates were compared by an all-against-all approach using BLASTP (Camacho et al., 2009) and grouped into orthologous clusters using GET_HOMOLOGUES (Version 2.0.10) (ContrerasMoreira and Vinuesa, 2013). Pan and core genomes were estimated using the pan-genomic analysis tool PanGP v.1.0.1 (Zhao et al., 2014). Orthologous groups (OGs) were identified via the Markov Cluster Algorithm (MCL) with an inflation value of 1.5 (Enright et al., 2002) and intersected using the compare_clusters.pl script provided with GET_HOMOLOGUES. The orthologous clusters were curated to exclude significantly divergent singletons, which is likely the result of erronous assembly or annotation. A presence/absence matrix for each gene cluster and each genome was constructed for the pan-genome before statistical and clustering analysis of the matrix was performed in $\mathrm{R}$ (http://www.r-project. org/). Hierarchal clustering of the pan-genome matrix was performed using complete-linkage UPGMA with Manhattan distances, and a distance cut-off for the number of clusters was determined using the knee of the curve approach (Salvador and Chan, 2004), binning the isolates into genomic lineages. The resulting distance-matrix was used to construct a heatmap with dendrograms using the heatmap.2 function included in the Gplots package (Version 2.16; Warnes et al., 2015) supplemented by the Dendextend package (Version 0.18.3; Galili, 2015).

\section{Comparative Genomics Analysis}

The genetic potential of individual Leuconostoc lineages that were identified by the pan-/core-genome analysis was investigated by producing intra-linage pan-genomes using GET_HOMOLOGUES (Version 2.0.10). The pan-genome for each lineage was analyzed using Blast2GO v4 (Conesa et al., 2005) to identify functionality, and Geneious 8.1.8 (Kearse et al., 2012) to identify sequence variation within orthologous clusters. The lineage pan-genomes were then compared using KEGG databases (Kanehisa and Goto, 2000) and the functional comparative comparison tool found in The SEED Viewer (Overbeek et al., 2014). CRISPR sequences and spacers were identified using the CRISPRFinder tool (Grissa et al., 2007).

\section{Relative Quantification of Leuconostoc Species in Starter Cultures}

Compositional analysis of Leuconostoc in five commercially available starter cultures was performed in triplicates on total DNA isolated from the starter cultures using $1 \mathrm{~mL}$ of starter culture diluted to an $\mathrm{OD}_{600}$ of 1 . The cultures were treated with $20 \mathrm{mg} / \mathrm{mL}$ lysozyme (Sigma-Aldrich) and $3 \mathrm{U} / \mathrm{L}$ mutanolysin (Sigma-Aldrich), mechanically lysed using FastPrep (MP Biomedicals) with $0.5 \mathrm{~g}$ of acid-washed beads $(<106 \mu \mathrm{m})$ (Sigma-Aldrich) and purified using the Qiagen DNeasy Blood \& Tissue Kit (Qiagen). A suitable amplicon target was identified by screening the core-genome for nucleotide sequence variation using the sequence alignment metrics functions available in the DECIPHER package v1.16.1 (Wright, 2015). Genes without flanking consensus regions within a 500 bp variable region adequate for differentiation, or did not provide sufficient discrimination from similar sequences in species likely to be present in dairy, were excluded. The locus eno encoding for enolase was amplified by PCR using the KAPA HiFi PCR Kit (KAPA Biosystems, Wilmington, Massachusetts, USA) with primers Eno-F (5'-AACACGAAGCTGTTGAATTGCGTG-3'), and Eno-R (5'-GCAAATCCACCTTCATCACCAACTGA-3'). Forward (5' TCGTCGGCAGCGTCAGATGTGTATAAGAGACAG-) and 
reverse (5'GTCTCGTGGGCTCGGAGATGTGTATAAGAGA CAG-) Illumina adapter overhangs were added to the $5^{\prime}$ end of the primers to allow for Nextera XT DNA indexing of the PCR-products. The resulting libraries were sequenced on an Illumina MiSeq with V3 $(2 \times 300 \mathrm{bp})$ reagents. The resulting data were paired-end-joined and quality filtered using PEAR (Zhang et al., 2014) and clustered with a 100\% identity level threshold using usearch v7 (Edgar, 2010) with error-minimization from uparse (Edgar, 2013). The resulting sequences were matched against a local BLAST-database produced from the Leuconostoc genomes for identification.

\section{RESULTS}

\section{Leuconostoc in Dairy Starters}

Enumeration on MRS-agar has been reported to underestimate the number of leuconostocs, especially Ln. cremoris (Vogensen et al., 1987; Ward et al., 1990; Auty et al., 2001). Bacterial counts were compared in five starter cultures (A, B, C, D, and E) commonly used in the production of Dutch-type cheeses using MRS and MPCA agar with $40 \mu \mathrm{g} / \mathrm{mL}$ vancomycin. The results (Figure 1) showed large differences in the counts between starter cultures for the two media. Cultures $\mathrm{A}$ and $\mathrm{D}$ gave substantially higher counts on MPCA compared to MRS, while cultures B, C, and $\mathrm{E}$ had similar counts on both media. Thus, cultures $\mathrm{A}$ and $\mathrm{D}$ seemed to contain a large number of Leuconostoc strains unable to grow on MRS, while cultures B, C, and E did not.

\section{Genome Sequencing and Pan-Genomic Analysis}

Leuconostoc diversity was investigated by whole-genome sequencing of 20 isolates picked from MPCA- and MRS-plates of cultures A and D, and 26 isolates from cheese, including Dutch-type cheese produced using cultures B, C, and E. Lastly, 13 publically available Leuconostoc spp. genomes were included in the dataset. All 59 Leuconostoc genomes were annotated and the coding sequences (CDS) were compared by a blast-allagainst-all approach to identify OGs. Pan- and core-genomes were estimated (Figure 2) using the pan-genomic analysis tool PanGP. After curation, the pan-genome was determined to consist of 4415 OGs, and a core-genome was found to comprise 638 OGs. Differentiation of isolates using hierarchal clustering on the pan-matrix clearly separated Leuconostoc species and sub-species (Figure 3). Several of the strains previously identified as $L n$. mesenteroides subspecies were shown to be $L n$. pseudomesenteroides by the genomic analysis. Moreover, the NCBI strain LbT16 previously identified as Ln. cremoris, was an outlier to the Ln. cremoris species branch and was identified in the pan-genomic analysis as Ln. mesenteroides. This was further confirmed by alignment of the full-length $16 \mathrm{~S}$ rRNA, revealing a $100 \%$ identity between Ln. cremoris LbT16 and Ln. mesenteroides type $16 \mathrm{~S}$ rRNA. Based on sequence similarity and gene content, the pan-genomic clustering divided the 59 leuconostocs into 12 robust Leuconostoc lineages across the genus. These included three lineages of Ln. cremoris (C1-C3), four lineages of $L n$. pseudomesenteroides (P1-P4), four lineages of Ln. mesenteroides (M1-M4), and one lineage of Ln. lactis (L1). The Ln. cremoris TIFN8 genome was excluded from further analysis because the genome data contained a high number of fragmented genes and redundant sequences, making it an outlier.

The differences between lineages (Table 1), species and subspecies level (in the case for Ln. mesenteroides subsp.) include significantly smaller genomes for $\mathrm{Ln}$. cremoris and Ln. lactis (1.6-1.8 Mb) compared to Ln. mesenteroides, Ln. dextranicum,

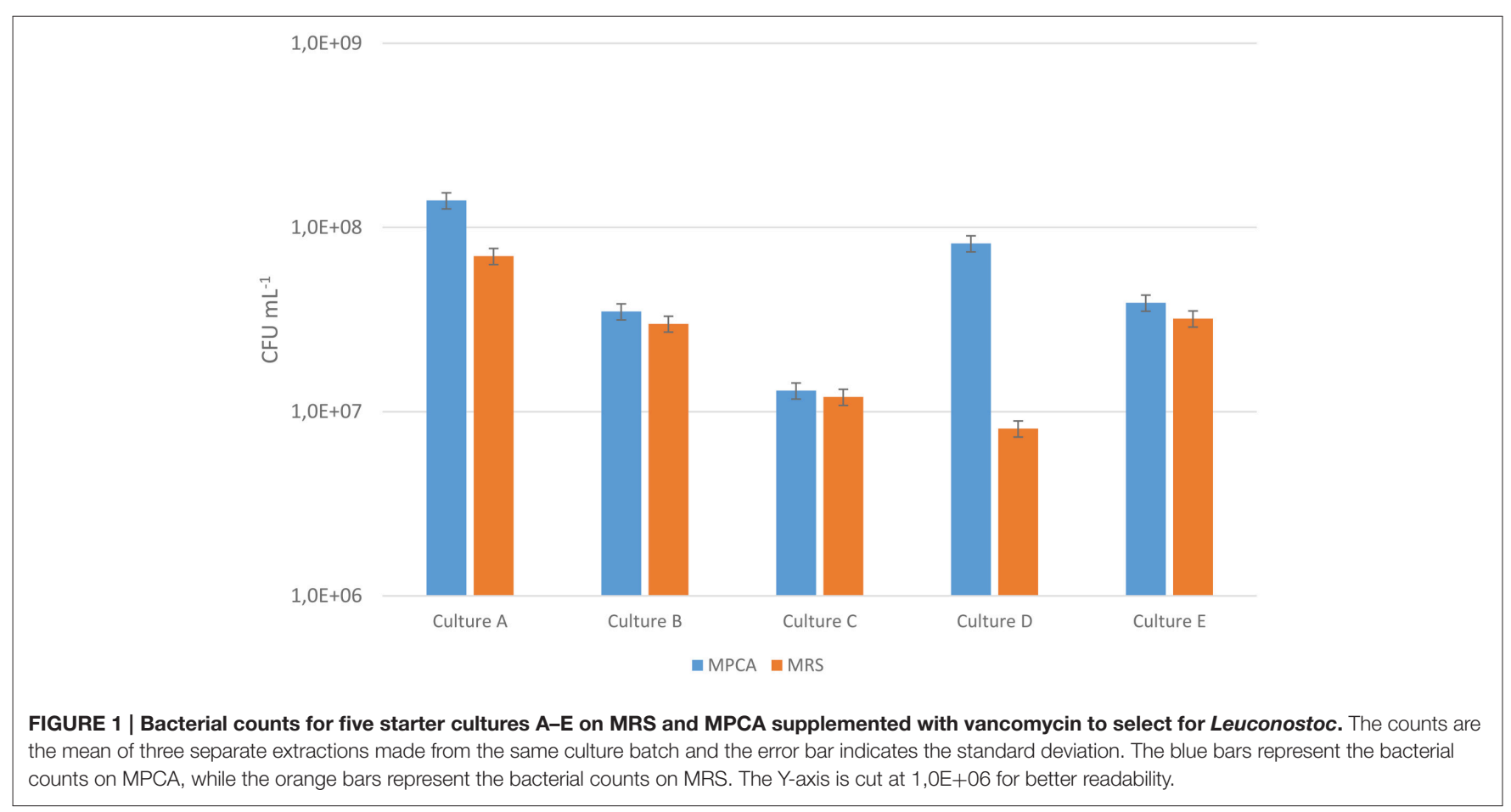




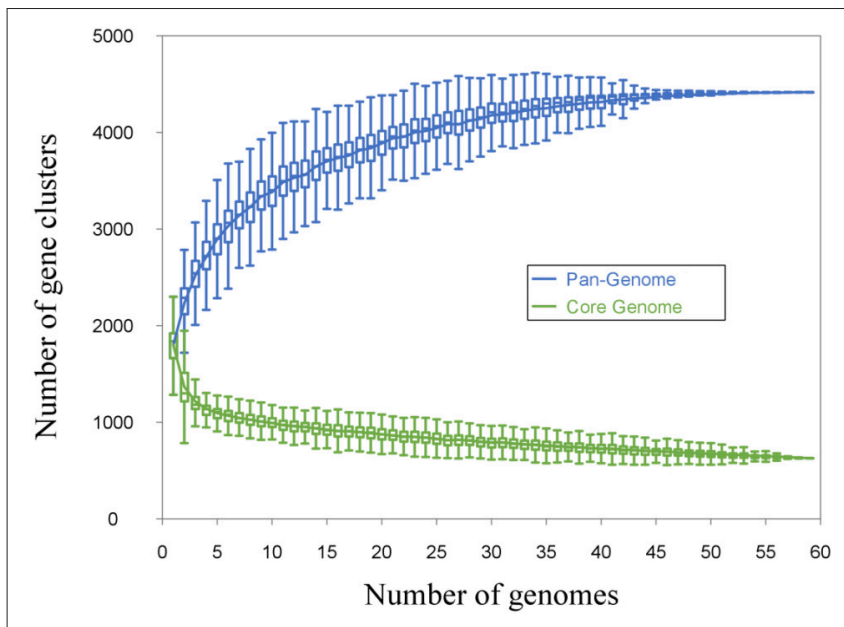

FIGURE 2 | Pan- and core-genome estimation. The estimation is made by including genomes one by one, matching the genetic content from each genome, with the growing pan- and the decreasing core-genome. Homologous genes are clustered together in orthologous groups. If the genomes included in the estimation are sufficiently distant from each other with regards to phylogeny, more than one orthologous group can exist for the same gene. The cut-off for this is set by the inflation value in the Markov Cluster Algorithm (MCL), for our dataset the inflation value was set to 1.5. The genetic content was curated for significantly divergent singletons, likely to be the product of erroneous assembly or annotation. The final pan-genome was estimated at 4415 orthologous groups, while the core-genome was estimated at 638 orthologous groups.

and Ln. pseudomesenteroides (1.8-2.2 Mb). Moreover, the larger genome found in the latter three species contained up to 400 more coding sequences (CDS) than Ln. cremoris and Ln. lactis. Analysis of functional genomics indicated a closer relationship between Ln. lactis and Ln. pseudomesenteroides, than that of $L n$. mesenteroides. Comparison of genetic potential within and between the Ln. mesenteroides subspecies showed only minor differences between Ln. mesenteroides and Ln. dextranicum. Rather, as shown in Figure 3, the variation between the isolates was much greater than the difference between Ln. mesenteroides and $L n$. dextranicum. On the other hand, substantial difference was found between isolates of dairy origin and non-dairy origin. This environment adaptation was also observed for Ln. lactis, where Ln. lactis 91922, isolated from kimchi was clearly distinguishable from LN19 and LN24 isolated from dairy. Comparison of Ln. cremoris and other Ln. mesenteroides subspecies isolates revealed that a range of genetic elements found in these species that were missing in Ln. cremoris. Apart from some enzymes encoding for rhamnose-containing glucans, Ln. cremoris isolates did not have any genetic functionality absent in Ln. mesenteroides or Ln. dextranicum. Moreover, several truncated genes and deletions were found in Ln. cremoris isolates, likely the result of a degenerative evolutionary process through a long period of growth in the milk environment.

\section{Comparative Genomics of Intra-Species Leuconostoc Lineages}

To explore differences in functional genetic potential between the lineages within the species and subspecies, comparative analysis of intra-lineage pan-genomes was performed. The results are included in Supplementary Table S2.

\section{(I) Ln. cremoris Lineages}

Comparison of the genetic content for $\mathrm{Ln}$. cremoris lineages showed that Ln. cremoris C1, C2, and C3 were highly similar and differentiated from each other mostly because of sequence variation in shared OGs. Ln. cremoris C1 (MPCA-type), which did not grow on MRS was missing four OGs found in both lineage C2 and C3 (MRS-type). These OGs were annotated $r m l A, r m l B$, $r m l C$, and $r m l D$, encoding for four enzymes identified in the subsystem "rhamnose containing glycans." These enzymes are associated with polysaccharide biosynthesis and their presence likely does not explain the inability of C1-type strains to grow on MRS.

\section{(II) Ln. mesenteroides and Ln. dextranicum Lineages}

Comparison of the genetic content showed a large variance between and within the $L n$. mesenteroides lineages. Interestingly, no major difference between subspecies $L n$. mesenteroides and Ln. dextranicum was found. Ln. dextranicum 20484 is grouped together with Ln. mesenteroides isolates LN32 and LN34, while $\mathrm{Ln}$. dextranicum LbE16 is grouped together with $\mathrm{Ln}$. mesenteroides LbE15 and LN08. This subspecies segregation of Ln. dextranicum and Ln. mesenteroides was based on the phenotypical ability to produce dextran from sucrose. Dextransucrase, the enzyme involved in this process, is a glucosyltransferase that catalyzes the transfer of glucosyl residues from sucrose to a dextran polymer and releases fructose. Several glucosyltransferases were found within all Ln. mesenteroides isolates included in this study, among them several genes encoding for dextransucrases with $40-67 \%$ amino acid identity to each other. Genotypically, the potential for dextran production exists within many if not all Ln. mesenteroides isolates, and does not differentiate $L n$. mesenteroides from Ln. dextranicum. This finding was manifest by the separation of $L n$. mesenteroides and Ln. dextranicum isolates into four lineages. Functional comparative analyses showed that the presence of the cit operon necessary for metabolism of citrate, and the lacLM genes is a characteristic of dairy-associated Ln. mesenteroides, Ln. cremoris and Ln. pseudomesenteroides. In all of the strains in lineages M3 and M4, both the cit operon and the lacLM genes were present, while strains in lineages M1 and M2 were lacking the cit operon, and half of them also lacked the lacLM genes. Furthermore, the strains in lineages M1 and M2 contained the genetic potential for metabolism of arabinose, and the two isolates J18 and ATCC8293 also contained genetic potential for xylose and $\beta$ glucoside metabolism. The lineage M4 strains LbT16 and LN05 also contained the deletion in the lac $Z$ gene which is commonly identified in Ln. cremoris type strains. A genetic potential for proteolysis of casein ( $p r t P)$ was identified in Ln. mesenteroides lineages M1 and M4, but not in M2 or M3.

\section{(III) Ln. lactis Lineages}

The pan-genomic differentiation grouped all the Ln. lactis isolates into one lineage. However, differences in genetic potential were found between the kimchi isolate Ln. lactis 91922 and 


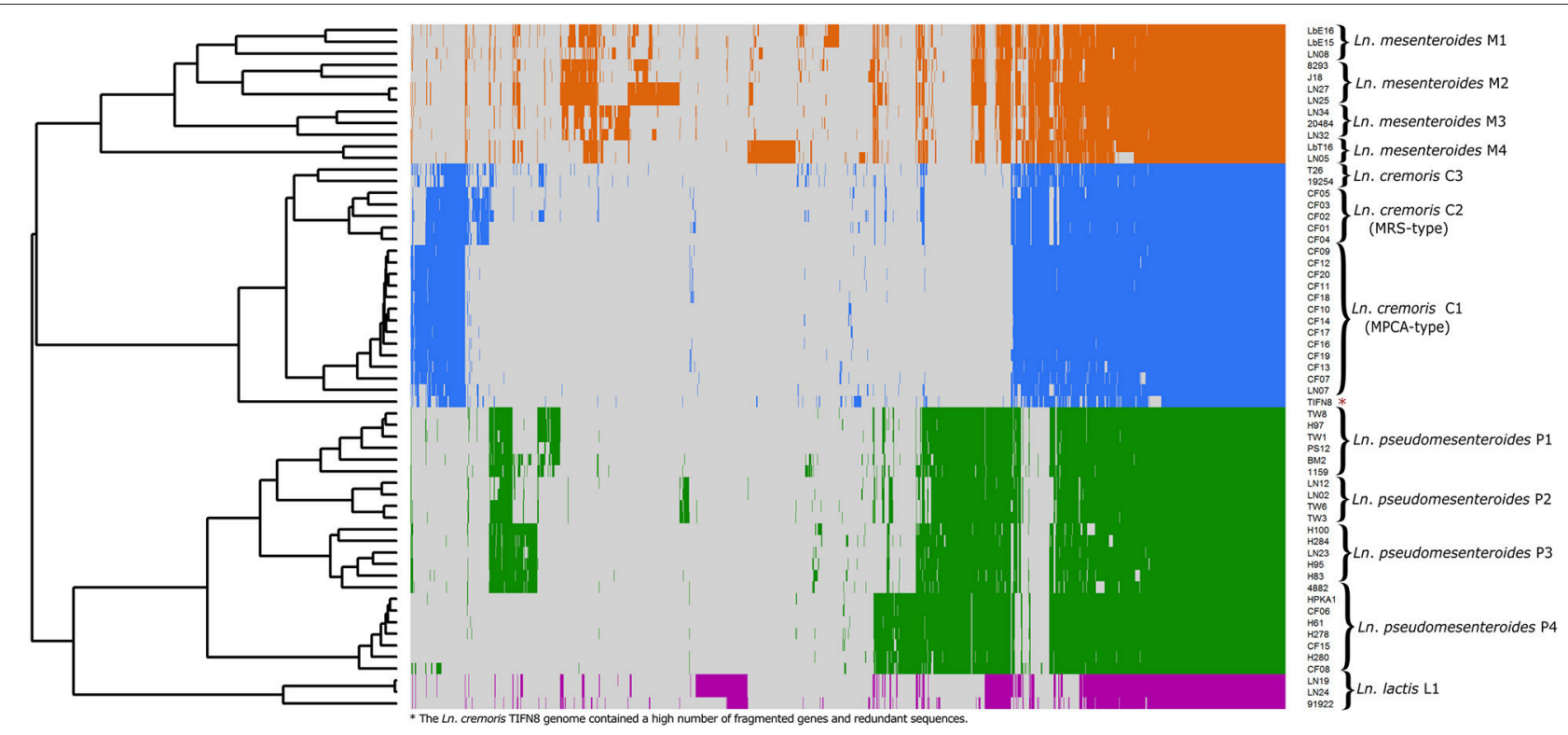

FIGURE 3 | Differentiation of $\mathbf{5 9}$ Leuconostoc genomes using the pan-genome of $\mathbf{4 4 1 5}$ oGs. Hierarchal clustering of genomes clearly separated Leuconostoc species and subspecies. Moreover, the high sensitivity of the method produced twelve robust Leuconostoc lineages annotated on the right side of the figure. Four lineages of Ln. mesenteroides (colored orange), three lineages of Ln. cremoris (colored blue), four lineages of $L n$. pseudomesenteroides (colored green), and one linage of $L n$. lactis (colored purple) are shown. $\left(^{*}\right)$ The $L n$. cremoris TIFN8 genome was excluded from further analysis because the genome data contained a high number of fragmented genes and redundant sequences. The heatmap was generated with $\mathrm{R}$ using the heatmap. 2 function included in the Gplots package supplemented by the Dendextend package.

dairy isolates LN19 and LN24. Ln. lactis 91922 lacked citrate metabolism genes citCDEFG, but carried genetic potential for a maltose and glucose specific PTS system, metabolism of arabinose and a CRISPR-Cas operon, that were not found in the other two Ln. lactis isolates.

\section{(IV) Ln. pseudomesenteroides Lineages}

Despite the significant pan-genomic differences and the sequence variation in shared OGs, the functional differences between lineages of $L n$. pseudomesenteroides were surprisingly few. Ln. pseudomesenteroides P4 was different from the other three lineages with regards to genome synteny and genetic potential. Genetic functionality in the category of methionine biosynthesis, $\beta$-glucoside metabolism, sucrose metabolism, as well as an additional lactate dehydrogenase was identified in $L n$. pseudomesenteroides $\mathrm{P} 4$ but not P1, P2, and P3. Moreover, P4 isolates were missing the genes for reduction of diacetyl to acetoin and 2,3-butandiol, and contained genes for a different capsular and extracellular polysaccharide biosynthesis pathway, compared to $\mathrm{P} 1, \mathrm{P} 2$, and $\mathrm{P} 3$ isolates.

\section{Genetic Potential of Leuconostoc (I) Amino Acid Biosynthesis}

The amino acid requirements of leuconostocs have been described as highly variable between strains. Glutamic acid and valine are required by most leuconostocs, methionine usually stimulates growth, while no Leuconostoc are reported to require alanine (Garvie, 1967). Comparative analysis of genes involved in amino acid biosynthesis showed that Ln. cremoris and Ln. mesenteroides subspecies carried the genetic potential to produce a wide range of amino acids while Ln. lactis and Ln. pseudomesenteroides did not (Table 2). This included genes encoding biosynthesis of histidine, tryptophan, methionine and lysine. Studies on the amino acid requirement of leuconostocs show that most of the $L n$. mesenteroides subspecies do require isoleucine and leucine to grow. The ilv and leu operons involved in biosynthesis of the branched-chain amino acids isoleucine, leucine and valine were present in all Ln. mesenteroides isolates, however both operons were truncated when compared to functional ilv and leu operons from lactococci. The leuA gene in the leuABCD operon is truncated in leuconostocs (391 aa) compared to lactococci (513 aa) likely resulting in an inactive product and a nonfunctional pathway. This has been documented in the dairy strain Lactococcus lactis IL1403 where a similar truncation of the leuA gene led to an inactivation of the leucine/valine pathway (Godon et al., 1993). Likewise, the $i l v$ operon of sequenced leuconostocs is missing the ilvD gene, and has truncated $i l v A$ and $i l v H$ genes when compared to the lactococcal ilv operon. The truncation of $i l v A$ has been shown to result in inactivation of the product, and would by itself be sufficient to abort the biosynthesis pathway (Cavin et al., 1999). None of the leuconostocs had genes for biosynthesis of glutamic acid. Ln. lactis isolates also lacked the genetic potential for cysteine biosynthesis.

\section{(II) Carbohydrate Metabolism}

Differences in the genetic potential within and between the Leuconostoc species were analyzed by comparing intra-species 
TABLE 1 | Average genome size and coding sequences of Leuconostoc isolates binned into pan-genome lineages.

\begin{tabular}{lcc}
\hline Profile name & Average genome size (Mb) & Average CDS \\
\hline Ln. cremoris C1 (MPCA-type) & $1.680( \pm 5)$ & $1760( \pm 20)$ \\
Ln. cremoris C2 (MRS-type) & $1.741( \pm 40)$ & $1822( \pm 30)$ \\
Ln. cremoris C3 & $1.765( \pm 124)$ & $1956( \pm 198)$ \\
Ln. mesenteroides M1 & $1.869( \pm 19)$ & $1851( \pm 7)$ \\
Ln. mesenteroides M2 & $2.150( \pm 123)$ & $2212( \pm 162)$ \\
Ln. mesenteroides M3 & $2.014( \pm 19)$ & $2074( \pm 18)$ \\
Ln. mesenteroides M4 & $2.061( \pm 219)$ & $2101( \pm 173)$ \\
Ln. pseudomesenteroides P1 & $2.028( \pm 47)$ & $2081( \pm 61)$ \\
Ln. pseudomesenteroides P2 & $1.921( \pm 25)$ & $1925( \pm 46)$ \\
Ln. pseudomesenteroides P3 & $2.063( \pm 44)$ & $2133( \pm 60)$ \\
Ln. pseudomesenteroides P4 & $2.032( \pm 61)$ & $2046( \pm 60)$ \\
Ln. lactis L1 & $1.718( \pm 26)$ & $1700( \pm 43)$ \\
\hline
\end{tabular}

Information on each individual isolate is included in Supplementary Table S1.

pan-genomes using Blast2GO and the Seed Viewer. The Leuconostoc genus is composed of heterofermentative bacteria that use the phosphoketolase pathway to ferment hexoses. Therefore, it was not surprising to find that none of the isolates contained the gene for phosphofructokinase, a key enzyme in the Embden-Meyerhof pathway. However, a gene encoding fructose-bisphosphate aldolase class II was present in Ln. lactis and Ln. pseudomesenteroides. This could indicate a potential for synthesis of fructose-1,6-bisphosphate and glyceraldehyde-3-phosphate through fructose-1-phosphate, and hence homofermentative breakdown of fructose in Ln. lactis and Ln. pseudomesenteroides.

Comparative analysis of genes related to carbohydrate metabolism revealed big differences between the species (Table 3). All leuconostocs in this study encode betagalactosidase, enabling utilization of lactose. Interestingly, the dairy $L n$. mesenteroides have two different beta-galactosidases, lac $Z$ and the plasmid-encoded lacLM (Obst et al., 1995), while the non-dairy isolates only contain lacZ. In Ln. cremoris, lacZ contains a large central deletion of 1200 bp between positions 740-1940. The Ln. lactis isolates only encode beta-galactosidase through lacZ, while the $L n$. pseudomesenteroides isolates only encode beta-galactosidase through lacLM. In Leuconostoc, lactose is taken up by the lactose-specific transporter LacS, which couples lactose uptake to the secretion of galactose. LacS contains a C-terminal EIIAGlc-like domain and in S. thermophilus it has been shown that this domain can be phosphorylated, causing an increased lactose uptake rate (Gunnewijk and Poolman, 2000). All Leuconostoc isolates have this gene, but in Ln. cremoris lacS is truncated and lacks the C-terminal domain, possibly affecting lactose uptake and hence, growth rate on lactose. Alignment of all lacS sequences from this study revealed a close relationship between Ln. pseudomesenteroides, Ln. lactis, and $L n$. mesenteroides isolates of non-dairy origin. In fact, lacS of non-dairy associated Ln. mesenteroides is more similar to the lacS from Ln. lactis and Ln. pseudomesenteroides (>75\% identity) than that of dairy-associated $L n$. mesenteroides or
TABLE 2 | Presence of genes encoding enzymes for amino acid biosynthesis.

\begin{tabular}{|c|c|c|c|c|}
\hline $\begin{array}{l}\text { Amino acid } \\
\text { pathway }\end{array}$ & $\begin{array}{l}\text { Ln. } \\
\text { cremoris }\end{array}$ & $\begin{array}{l}\text { Ln. } \\
\text { mesenteroides }\end{array}$ & $\begin{array}{l}\text { Ln. } \\
\text { lactis }\end{array}$ & $\begin{array}{c}\text { Ln. } \\
\text { pseudomesenteroides }\end{array}$ \\
\hline Alanine & + & + & + & + \\
\hline Arginine & + & + & + & + \\
\hline Aspartate & + & + & + & + \\
\hline Cysteine & + & + & - & + \\
\hline Glutamine & - & - & + & + \\
\hline $\begin{array}{l}\text { Glutamic } \\
\text { acid }\end{array}$ & - & - & - & - \\
\hline Glycine & + & + & + & + \\
\hline Histidine & + & + & - & - \\
\hline Isoleucine & - & - & - & - \\
\hline Leucine & - & - & - & - \\
\hline Lysine & + & + & + & - \\
\hline Methionine & + & + & - & - \\
\hline Phenylalanine & + & + & + & + \\
\hline Proline & + & + & + & + \\
\hline Serine & + & + & + & + \\
\hline Threonine & + & + & + & + \\
\hline Tryptophan & + & + & - & - \\
\hline Tyrosine & + & + & + & + \\
\hline Valine & - & - & - & - \\
\hline
\end{tabular}

+, presence of predicted pathway functionality; -, absence of predicted pathway functionality.

Ln. cremoris ( $<36 \%$ identity). Genes coding for maltosephosphorylase (malP) and sucrose-6-phosphate hydrolase $(s c r B)$ were found in Ln. lactis, Ln. pseudomesenteroides P4, and Ln. mesenteroides, but not Ln. cremoris. These enzymes are central to the metabolism of maltose and sucrose. Isolates containing malP also contained genes malR and malL, as well as a maltose epimerase. Ln. lactis and Ln. pseudomesenteroides also contained the malEFG gene cluster encoding for an $\mathrm{ABC}$ transporter, however the malEFG genes were truncated in $L n$. pseudomesenteroides. Genes encoding for $\beta$-glucosidase (bglA) enabling utilization of salicin and arbutin was found in all $L n$. pseudomesenteroides and Ln. lactis isolates, as well as in Ln. mesenteroides M2 isolates. The bglA gene, was found to be present in all Ln. cremoris isolates, as well as Ln. mesenteroides M1, M3, and M4 isolates, however the gene was truncated and was identified as inactive by the Seed Viewer. A genetic potential for metabolism of trehalose was found, annotated as treA in Ln. mesenteroides and the Ln. lactis of dairy origin, and as TrePP in Ln. pseudomesenteroides and Ln. lactis 91922. Genes encoding for trehalose transport were not found in Ln. mesenteroides M3 and M4, indicating that these lineages are not able to metabolize trehalose from the environment. Xylose isomerase $(x y l A)$ and xylose kinase $(x y l B)$ genes were found in all Leuconostoc isolates, but the genes were heavily truncated in Ln. cremoris isolates and Ln. mesenteroides M3 and M4 isolates. Isolates with full length $x y l A$ and $x y l B$ genes also contained the gene $x y l G$, encoding for a xylose transport protein. 
TABLE 3 | Genetic potential for metabolism of carbohydrates indicated by the presence or absence of enzymes crucial to metabolism of substrates.

\begin{tabular}{|c|c|c|c|c|c|c|c|c|c|c|c|c|}
\hline Gene(s) & \multicolumn{3}{|c|}{ Ln. cremoris } & \multicolumn{4}{|c|}{ Ln. mesenteroides } & \multicolumn{4}{|c|}{ Ln. pseudomesenteroides } & $\begin{array}{l}\text { Ln. lactis } \\
\text { L1 }(n=3)\end{array}$ \\
\hline malP & - & - & - & \# & + & + & - & + & + & + & + & + \\
\hline malEFG & - & - & - & - & - & - & - & $\#$ & $\#$ & $\#$ & $\#$ & + \\
\hline malx & - & - & - & - & - & - & - & - & - & - & - & + \\
\hline malR & - & - & - & + & + & + & - & + & + & + & + & + \\
\hline lack & + & + & + & $+(66 \%)$ & $+(50 \%)$ & + & + & + & + & + & + & - \\
\hline lacM & + & + & + & $+(66 \%)$ & $+(50 \%)$ & + & + & + & + & + & + & - \\
\hline $\operatorname{lac} Z$ & $\#$ & $\#$ & $\#$ & + & + & $\#$ & $\#$ & - & - & - & - & + \\
\hline lacs & \# & $\#$ & $\#$ & + & + & + & + & + & + & + & + & + \\
\hline galEKT & + & + & + & + & $+(75 \%)$ & + & + & + & + & + & + & + \\
\hline$x y \mid A B G$ & $\#$ & $\#$ & $\#$ & + & + & $\#$ & $\#$ & + & + & + & + & + \\
\hline treA & - & - & - & + & + & + & + & - & - & - & - & $\#(66 \%)$ \\
\hline trePP & - & - & - & - & - & - & - & + & + & + & + & $+(33 \%)$ \\
\hline bglA & $\#$ & $\#$ & $\#$ & $\#$ & + & $\#$ & $\#$ & + & + & + & + & + \\
\hline fruA & - & - & - & - & - & - & - & - & - & - & - & + \\
\hline levE & - & - & - & - & + & + & + & + & + & + & + & - \\
\hline frk & $\#$ & $\#$ & $\#$ & + & + & + & + & + & + & + & + & + \\
\hline citCDEFGOS & + & + & + & + & $+(50 \%)$ & - & + & + & + & + & + & $+(66 \%)$ \\
\hline$f b a$ & - & - & - & - & - & - & - & + & + & + & + & + \\
\hline
\end{tabular}

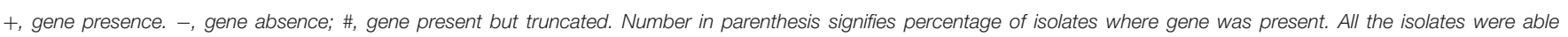
to metabolize glucose and lactose. The number given in parenthesis is given for the percentage of isolates within the lineage with the gene. Genes are abbreviated as follows: araBAD, arabinose metabolism pathway; malP, maltose phosphorylase; malEFG, maltose transport genes; malX, maltose/maltodextrin binding precursor; mall, sucrose-isomaltose; malR, maltose operon regulatory gene; lacL, beta-galactosidase, big subunit; lacM, beta-galactosidase, small subunit; lacZ, beta-galactosidase; lacS, lactose permease; galEKT, galactose metabolism; manXYZ, mannose transport genes; manA, mannose-6-phosphate isomerase; scrB, sucrose-6-phosphate hydrolase; xylABG, xylose isomerase, xylose kinase, xylose transport protein; treA, trehalose-6-phosphate hydrolase; trePP, trehalose-6-phosphate phosphorylase; bglA, beta-D-glucosidase; fruA and levE, fructose PTS; frk, fructokinase; citCDEFGOS, citrate metabolism operon; fba, fructose bisphosphate aldolase

\section{(III) Citrate Metabolism}

All the dairy strains in this study contained the genes necessary for uptake and metabolism of citrate. These genes are found in an operon comprised of citC (citrate lyase ligase), citDEF (citrate lyase), $c i t G$ (holo-ACP synthase), citO (transcriptional regulator) and citS $(\mathrm{Na}+$ dependent citrate transporter). A citrate/malate transporter annotated cimH was present in Ln. mesenteroides subspecies isolates, but was not present in any of the Ln. lactis or Ln. pseudomesenteroides isolates. In the Ln. cremoris and Ln. pseudomesenteroides genomes, the cit operon is flanked by two IS116/IS110/IS902 family transposases, suggesting it may have been acquired by horizontal gene transfer. In these bacteria, the operon appears to be located on the chromosome, a finding supported by the genome assembly, which organizes the cit operon on a contig containing a number of essential genes, and by read coverage analysis that shows a continuous gapless coverage through the contig, with no elevation in read coverage across the cit operon. The citCDEFGOS operons of Ln. mesenteroides and Ln. lactis, however, appear to be located on a plasmid, since in all cases they assembled on a contig, which includes a site of replication and not essential genes. The cit operon is highly conserved in the Ln. cremoris and Ln. pseudomesenteroides genomes with $>97 \%$ DNA sequence identity between all the isolates. The likely to be plasmid-encoded cit operon found in Ln. mesenteroides and Ln. lactis genomes is also highly conserved between the isolates ( $>99 \%$ identity), however it is significantly different from the chromosomally encoded cit operon present in Ln. cremoris and Ln. pseudomesenteroides (50-65\% DNA sequence identity for each gene). None of the strains of nondairy origin included in this study contained the citrate genes, indicating that the ability to metabolize citrate plays an important role in the successful adaption to the milk environment.

\section{(IV) Proteolytic Activity}

Leuconostocs grow in association with the lactococci in dairy fermentations, and commonly grow poorly in milk without the presence of lactococci. The general explanation for this poor growth is their lack of proteinase activity, making them dependent on small peptides from lactococcal proteinase activity. Screening all the isolates for genes involved in peptide and proteolytic activity revealed a number of differences between the lineages (Table 4). The genes encoding for the OppABCDF 
TABLE 4 | Genetic potential for proteolytic activity.

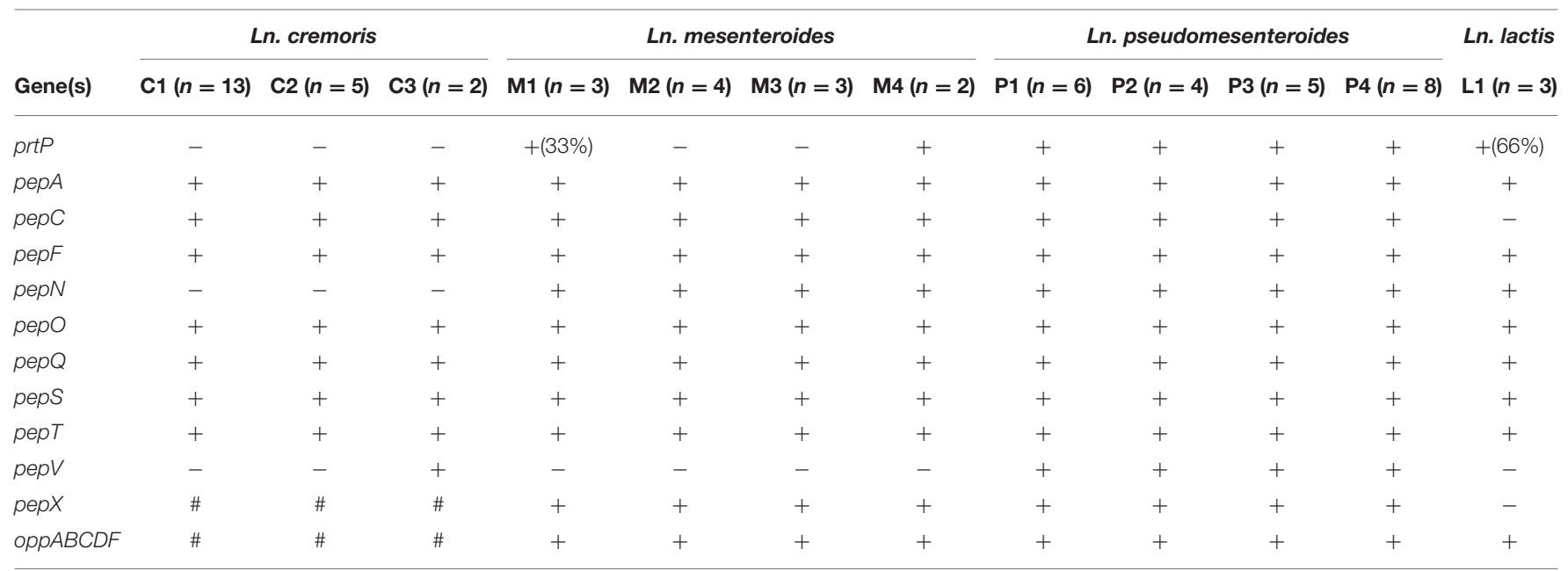

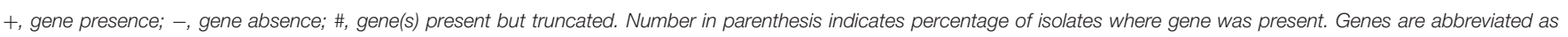

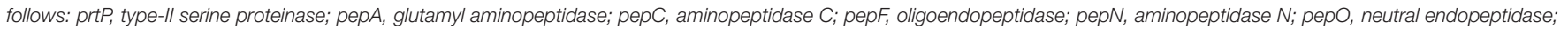
pepS, aminopeptidase; pepT, peptidase T; pepV, beta-ala-xaa dipeptidase; pepX, xaa-pro dipeptidyl-peptidase; oppABCDF, peptide ABC transporter operon.

system were found in all Leuconostoc genomes. However, in $\mathrm{Ln}$. cremoris genomes, the oppA gene was missing, and the $о p p B$ gene was severely truncated. A gene encoding for a PII-type serine proteinase (PrtP) best known for its action on caseins was found in all Ln. pseudomesenteroides genomes, dairy Ln. lactis genomes, Ln. mesenteroides M4 and 33\% of Ln. mesenteroides M1 genomes. All the sequenced Leuconostoc strains coded for a range of peptidases and aminotransferases. The Ln. cremoris isolates did not contain the pepN gene, but had the other general aminopeptidase gene, $p$ epC, which was found to be missing from $L n$. lactis genomes. The $p e p X$ gene, encoding for the enzyme $\mathrm{x}$-prolyl dipeptidyl aminopeptidase was truncated in Ln. cremoris (534 amino acids) compared to the pepX of other Leuconostoc strains (778-779 amino acids). The pepA, pepF, pepO, pepQ, pepS, and pepT genes were present in all Leuconostoc isolates. Finally, all Ln.pseudomesenteroides have the pep $V$ gene, encoding $\beta$-ala-dipeptidase. This dipeptidase has been shown to cleave dipeptides with an $\mathrm{N}$-terminal $\beta$-Ala or $\mathrm{D}$-ala residue, such as carnosine and to a lesser extent, was shown to catalyze removal of N-terminal amino acids from a few distinct tripeptides in Lactobacillus delbrueckii subsp. lactis (Vongerichten et al., 1994).

\section{CRISPR-Cas in Ln. lactis and}

\section{Ln. pseudomesenteroides}

Ln. lactis 91922 and all the Ln. pseudomesenteroides isolates included in this study contained CRISPR-Cas genes with repeat regions.

\section{Composition of Leuconostocs in Starter Cultures}

The Leuconostoc core gene library was used to devise a scheme for species and subspecies quantification in starter cultures by amplicon sequencing. Core genes were screened for sequence variation and for targeted-amplicon suitability. After curation, the top three candidates were $16 \mathrm{~S}$ rRNA, rpoB, and eno. While the full-length 16S rRNA sequence enables differentiation of species and subspecies, any region shorter than 500 bp is only able to differentiate between species, and then only when using the nucleotides between position 150-550, encompassing the V2 and $\mathrm{V} 3$ regions of $16 \mathrm{~S}$ rRNA. However, the sequences of $16 \mathrm{~S}$ rRNA and the $r p o B$ loci were too similar to the same genes in lactococci to allow for primer design specific for leuconostocs, and thus were unsuitable for quantification of leuconostocs. The gene encoding enolase (eno) did allow for Leuconostoc specific primer design, and was used in targeted-amplicon sequencing to analyze the diversity of leuconostocs in the five starter cultures. The analysis revealed great differences between the starter cultures (Figure 4). Ln. cremoris dominated the Leuconostoc populations in cultures $\mathrm{A}, \mathrm{D}$ and $\mathrm{E}, \mathrm{Ln}$. pseudomesenteroides was most abundant in cultures B and C. Most of the Ln. cremoris in cultures $\mathrm{A}$ and D were of the MPCA type ( $\mathrm{Ln}$. cremoris $\mathrm{C} 1$ ) unable to grow on MRS, while MRS type Ln. cremoris dominated in culture E (data not shown). Relatively low levels of Ln. mesenteroides and $L n$. dextranicum were found in all cultures, the highest being $14 \%$ in culture B. Ln. lactis was only found in one of the starter cultures, culture E, where it constituted $17 \%$ of the leuconostocs.

\section{DISCUSSION}

Decades have passed since Dr. Ellen Garvie laid the foundation for the taxonomy of dairy relevant leuconostocs, and Dr. John Farrow expanded this list to include Ln. pseudomesenteroides. Their work has been the basis for classification of leuconostocs since then.

The Ln. pseudomesenteroides species was described for the first time in 1898 (Farrow et al., 1989), however its presence in a dairy starter culture was not described before 2014 (Pedersen et al., 2014b). Identification of leuconostocs by phenotypical traits or by partial 16S rRNA sequencing does not reliably distinguish between all species and misidentification has been 


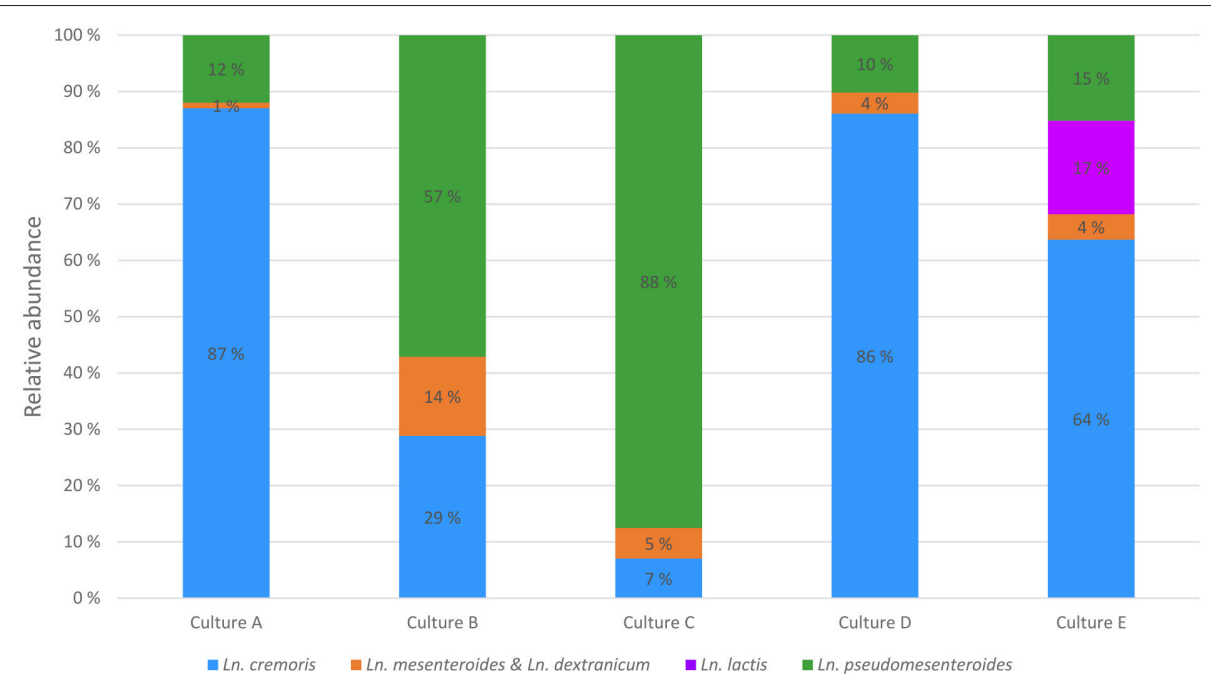

FIGURE 4 | Composition of leuconostocs in five starter cultures A-E using targeted-amplicon sequencing of the eno gene.

common. After genomic analysis, several isolates previously identified as $L n$. mesenteroides subspecies proved to be $L n$. pseudomesenteroides and isolates may have been misidentified in other studies as well. Surprisingly, the strain LbT16 (Accession. No: LAYV00000000) reported to be Ln. cremoris by Campedelli et al. (2015) was identified as Ln. mesenteroides when characterized by its genomic content and its full length $16 \mathrm{~S}$ rRNA sequence. Misidentification of Ln. cremoris is also uncommon. Compared to other dairy leuconostocs, Ln. cremoris grow slower, to a lower density and not at temperatures of $30^{\circ} \mathrm{C}$ or higher. In addition, a large proportion of $\mathrm{Ln}$. cremoris type strains are not able to grow on MRS. These characteristics provide the means for reliable phenotypical identification of Ln. cremoris. However, phenotypical differentiation between other $L n$. mesenteroides subspecies, Ln. lactis and Ln. pseudomesenteroides remains unreliable. In this study, dairy relevant leuconostocs are characterized using a genomics approach and the diversity of leuconostocs in five commercial DL-type starter cultures is analyzed.

The genomic analysis clearly separated leuconostocs by species, subspecies, and enabled intra-species differentiation. Interestingly, the genomic analysis did not distinguish $\mathrm{Ln}$. dextranicum from Ln. mesenteroides. The strain-to-strain variation was higher than the differences between subspecies. The dextranicum subspecies has been previously defined by phenotypical traits only and separate subspecies distinction is not justified by the genomic data of this study. On the other hand, the pan-genomic analysis separated Ln. mesenteroides isolates by habitat. The dairy strains clearly differ from those isolated from plant material, the former have smaller genomes and utilize a more restricted range of carbohydrates. The two subspecies $L n$. mesenteroides and Ln. cremoris share a large amount of genetic content with high identity scores, reflecting a close phylogenetic relationship. However, many genes present in Ln. mesenteroides are found to be truncated, contain deletions or are completely missing in Ln. cremoris. Adaptation of dairy strains to the milk environment involved acquisition of the plasmid-encoded lacLM by horizontal gene transfer (Obst et al., 1995), which in turn permitted loss of a functional lacZ. Some of the dairy Ln. mesenteroides, and all of the Ln. cremoris isolates carry a deletion in the lac Z gene. The dairy Ln. mesenteroides and in particular Ln. cremoris display telltale signs of a prolonged degenerative evolution, likely the result of a long period of growth in milk. In this environment, the leuconostocs have evolved alongside lactococci. All the dairy strains included in this study contain the cit operon comprised of citC (citrate lyase ligase), citDEF (citrate lyase), citG (holo-ACP synthase), citO (transcriptional regulator) and citS $\left(\mathrm{Na}^{+}\right.$dependent citrate transporter). The citCDEFGOS operon organization is different from the operon in Lactococcus lactis, which lacks citO and the citS transporter (Drider et al., 2004). In citrate positive Lactococcus lactis, homologs of citO (citR) and the citS (citP) are located on a plasmid (Magni et al., 1994). The presence of the citCDEFGOS genes enable so-called citrolactic fermentation, co-metabolism of sugar and citrate providing the cells with higher energy yield and proton motive force (Marty-Teysset et al., 1996). In Ln. lactis and Ln. mesenteroides, this operon has been linked to a $\sim 22-\mathrm{kb}$ plasmid, inferred by phenotypical studies in combination with monitoring the presence of mobile genetic elements (Lin et al., 1991; Vaughan et al., 1995). In the study by Vaughan et al. (1995), Ln. mesenteroides was shown to retain its ability to metabolize citrate after losing three of its four plasmids. Moreover, after curing, a derivative isolate without the ability to degrade citrate still contained the fourth plasmid. Our data indicates that for Ln. cremoris and Ln. pseudomesenteroides, this is not the case. In all the Ln. cremoris and Ln. pseudomesenteroides genomes included in this study, the cit operon is located on the chromosome in a region with mobile element characteristics. A low level of genetic drift is indicated by the high sequence similarity between the cit operons of Ln. cremoris and Ln. pseudomesenteroides suggesting that the acquisition of these genes is quite recent, 
possibly from a common donor. The chromosomally encoded cit operon of Ln. cremoris and Ln. pseudomesenteroides was significantly different from the highly conserved and likely to be plasmid-encoded cit operon found in Ln. lactis and Ln. mesenteroides. These results indicate that the plasmid encoded cit operon originates from a different source and time. None of the strains of non-dairy origin included in this study contained the citrate metabolism genes, indicating that the ability to metabolize citrate also plays an important role in the successful adaption to the milk environment. The manufacture of Dutch-type cheeses has been going on for centuries and the starter cultures have been maintained by so-called "back slopping" for the last one and a half century, where new milk is inoculated with whey from the previous batch. This technique for propagating starter cultures is still being used and recent studies have shown that the complex starter cultures maintain a highly stable composition with regards to lactococci (Erkus et al., 2013). Culture composition may change over a short period of time depending on growth conditions and bacteriophage predation, but the microbial community is sustained in the long run. In this study, we show a large variation in the amount and composition of the Leuconostoc populations in cheeses starter cultures. Three of the starter cultures (A, D, and E) were dominated by Ln. cremoris, and for culture A and D, the majority of these were unable to grow on MRS. The other two starter cultures (B and C) were dominated by Ln. pseudomesenteroides. Interestingly, the cultures dominated by $L n$. cremoris also contain Ln. pseudomesenteroides strains. Ln. pseudomesenteroides growth rates in pure culture are significantly higher than that of Ln. cremoris at temperatures above $20^{\circ} \mathrm{C}$, so the microbial community is preserved, either by the starter culture developers, or by the microbial community itself. Little knowledge exists on how the diversity of leuconostocs is affected by manufacturing procedures. According to Thunell (1995) and Vedamuthu (1994) the only leuconostocs relevant in dairy are Ln. cremoris and $L n$. lactis, but in this study, Ln. lactis was detected only in culture E, which was dominated by Ln. cremoris. In two of the starter cultures studies in this work, $L n$. pseudomesenteroides was the dominating Leuconostoc, which shows that they are highly relevant in the production of cheese. This is also reflected by recent studies, where the presence of $L n$. pseudomesenteroides is more frequently reported (Callon et al., 2004; Porcellato and Skeie, 2016; Østlie et al., 2016). It is tempting to speculate that starter culture manufacturers have altered the conditions for culture propagation or manipulated the strain collections, thereby altering the culture dynamics between strains in favor of Ln. pseudomesenteroides.

The differences between the starter cultures could have an impact on the characteristics of the cheese product. Ln. cremoris lacks a wide range of genes involved in carbohydrate metabolism and proteolytic activity, and studies have shown that Ln. cremoris and Ln. pseudomesenteroides differ significantly in their ability to produce a wide range of volatile compounds (Pedersen et al., 2016). Most notably, the amount of acetoin and diacetyl in model-cheeses produced with only Ln. pseudomesenteroides was negligible. This was supported by our data, which showed that the Ln. pseudomesenteroides $\mathrm{P} 4$ isolates lack the genes necessary for reduction of diacetyl to acetoin and 2,3-butandiol. In addition, these isolates lacked the genes $i l v B$ and $i l v H$ encoding acetolactate synthetase large and small subunits, which is found in all $L n$. mesenteroides subspecies isolates. However, a different gene als $S$, encoding the same function, was found in all leuconostocs, including Ln. pseudomesenteroides. Studies on $\alpha$-acetolactate synthase (ALS) and $\alpha$-acetolactate decarboxylase (ALDC) activity in Ln. mesenteroides subspecies and Ln. lactis showed that the activity of both ALS and ALDC was higher for Ln. lactis (which does not have the ilv or leu operon) than that of Ln. cremoris (which does have part of these two operons) (Monnet et al., 1994). For comparison, the ALS activity of Lc. lactis biovar diacetylactis was comparable or in some cases even higher than that of $L n$. lactis. Ln. pseudomesenteroides was not included in the study, but data from semi-hard cheeses comparing the acetoin and diacetyl concentrations revealed lower concentrations in mock starters containing Ln. pseudomesenteroides compared to mock starters containing Ln. cremoris (Pedersen et al., 2016). This observation could be attributed to the rapid growth rate of $L n$. pseudomesenteroides when compared to that of Ln. cremoris. The presence of the degenerated ilv and leu operons could somehow be negative to Ln. cremoris growth rate. Indeed, when cloning of the ilv operon into Escherichia coli, the presence of Leuconostoc $i l v B$ was strongly detrimental to growth, while recombinant strains with an insertion in the Leuconostoc ilvB genes displayed normal growth. Their hypothesis was that expression of $i l v B$ without a functional branched chain amino acid biosynthesis mechanism could interfere with energy metabolism via pyruvate (Cavin et al., 1999).

In dairy fermentations, the leuconostocs grow in association with the lactococci. Whether the associative growth is of mutual benefit to the leuconostocs and lactococci has not been determined. Literature often attributes the poor growth of leuconostocs to the lack of protease activity (Vedamuthu, 1994; Thunell, 1995). However, the ability to acidify milk in pure culture has been described for $L n$. pseudomesenteroides (Cardamone et al., 2011), and we identified genetic potential for caseinolytic activity in Ln. pseudomesenteroides in our data. This would enable Ln. pseudomesenteroides to grow better in milk than $\mathrm{Ln}$. cremoris, which lacks the capacity for protease, as well as a functional peptide uptake system due to the lack of OppA, which is responsible for the uptake of extracellular peptides. An argument for mutually beneficial growth has been made by superimposing metabolic pathways from lactococci and leuconostocs, indicating a potential for metabolic complementation between the two genera (Erkus et al., 2013). One can be forgiven for thinking Ln. pseudomesenteroides the better bacteria of the two based on these tidbits of information alone. However, both Ln. cremoris and Ln. pseudomesenteroides have shown to be significant to the production of cheeses. It is difficult to conclude which Leuconostoc species produces the highly subjective matter of the better cheese product. The concentration of volatile compounds, fatty acid derivatives, acetoin, diacetyl, and amino acid derivates in products have been shown to diverge significantly, depending on which Leuconostoc species is added to the mixture of lactococci (Pedersen et al., 2016). 
In conclusion, the dairy-associated leuconostocs are highly adapted to grow in milk. Comparative genomic analysis reveals great differences between the Leuconostoc species and subspecies accustomed to the dairy environment, where they grow in association with the lactococci. The composition of the Leuconostoc population is significantly different between commercial starter cultures, which ultimately affects the characteristics and quality of the product. A better understanding of Leuconostoc microbial dynamics and the functional role of different dairy leuconostocs could be of great importance and be an applicable tool in ensuring consistent manufacture of high quality product. Currently, no detailed information on the relative amount or diversity of the Leuconostoc population in starter cultures is available to the industry. We provide a culture independent method for robust identification and quantification of Leuconostoc species in mixed microbial communities, enabling quantification of leuconostocs in starter cultures, as well as monitoring the diversity of leuconostocs through the cheese production process.

\section{AUTHOR CONTRIBUTIONS}

CF isolated and sequenced bacterial strains, performed the sequencing work in Norway (of all CF and $\mathrm{H}$-isolates in addition to all amplicon sequencing), analyzed the data, wrote the R-scripts, devised the methods and wrote the manuscript.

\section{REFERENCES}

Alegria, A., Delgado, S., Florez, A. B., and Mayo, B. (2013). Identification, typing, and functional characterization of Leuconostoc spp. strains from traditional, starter-free cheeses. Dairy Sci. Technol. 93, 657-673. doi: 10.1007/s13594-013-0128-3

Ardö, Y., and Varming, C. (2010). Bacterial influence on characteristic flavour of cheeses made with mesophilic DL-starter. Aust. J. Dairy Technol. 65, 153-158.

Auty, M. A., Gardiner, G. E., McBrearty, S. J., O’Sullivan, E. O., Mulvihill, D. M., Collins, J. K., et al. (2001). Direct in situ viability assessment of bacteria in probiotic dairy products using viability staining in conjunction with confocal scanning laser microscopy. Appl. Environ. Microbiol. 67, 420-425. doi: 10.1128/AEM.67.1.420-425.2001

Bandell, M., Lhotte, M. E., Marty-Teysset, C., Veyrat, A., Prévost, H., Dartois, V., et al. (1998). Mechanism of the citrate transporters in carbohydrate and citrate cometabolism in Lactococcus and Leuconostoc species. Appl. Environ. Microbiol. 64, 1594-1600.

Barrangou, R., Yoon, S. S., Breidt, F. Jr., Fleming, H. P., and Klaenhammer, T. R. (2002). Characterization of six Leuconostoc fallax bacteriophages isolated from an industrial sauerkraut fermentation. Appl. Environ. Microbiol. 68, 5452-5458. doi: 10.1128/AEM.68.11.5452-5458.2002

Björkroth, K. J., Geisen, R., Schillinger, U., Weiss, N., De Vos, P., Holzapfel, W. H., et al. (2000). Characterization of Leuconostoc gasicomitatum sp. nov., associated with spoiled raw tomato-marinated broiler meat strips packaged under modified-atmosphere conditions. Appl. Environ. Microbiol. 66, 3764-3772. doi: 10.1128/AEM.66.9.3764-3772.2000

Callon, C., Millet, L., and Montel, M. C. (2004). Diversity of lactic acid bacteria isolated from AOC Salers cheese. J. Dairy Res. 71, 231-244. doi: 10.1017/S0022029904000159

Camacho, C., Coulouris, G., Avagyan, V., Ma, N., Papadopoulos, J., Bealer, K., et al. (2009). BLAST+: architecture and applications. BMC Bioinformatics 10:421. doi: 10.1186/1471-2105-10-421
$\mathrm{FB}, \mathrm{H} \varnothing, \mathrm{TP}, \mathrm{HK}$, and $\mathrm{HN}$ provided bacterial isolates for a larger diversity. WK and $\mathrm{LH}$ performed the sequencing of isolates in Denmark. Supervision of danish activities was provided by FV. Supervision of Norwegian activities was provided by $\mathrm{HK}, \mathrm{H} \varnothing$, and $\mathrm{HH}$. All co-authors were involved in reviewing and commenting on the manuscript prior to its submission. A large contribution to final editing was made by $\mathrm{HN}$ and JB.

\section{FUNDING}

This work was funded by the Norwegian Research Council, TINE SA, and the Danish Council for Independent Research.

\section{ACKNOWLEDGMENTS}

We are grateful to TINE SA for providing culture samples and Dorota Dynda for providing isolates from Twarog. This work was funded by the Norwegian Research Council, TINE SA, and the Danish Council for Independent Research.

\section{SUPPLEMENTARY MATERIAL}

The Supplementary Material for this article can be found online at: http://journal.frontiersin.org/article/10.3389/fmicb. 2017.00132/full\#supplementary-material

Campedelli, I., Flórez, A. B., Salvetti, E., Delgado, S., Orrù, L., Cattivelli, L., et al. (2015). Draft genome sequence of three antibiotic-resistant Leuconostoc mesenteroides strains of dairy origin. Genome Announc. 3:e0101815. doi: 10.1128/genomeA.01018-15

Cardamone, L., Quiberoni, A., Mercanti, D. J., Fornasari, M. E., Reinheimer, J. A., and Guglielmotti, D. M. (2011). Adventitious dairy Leuconostoc strains with interesting technological and biological properties useful for adjunct starters. Dairy Sci. Technol. 91, 457-470. doi: 10.1007/s13594-011-0022-9

Cavin, J. F., Dartois, V., Labarre, C., and Diviès, C. (1999). Cloning of branched chain amino acid biosynthesis genes and assays of $\alpha$-acetolactate synthase activities in Leuconostoc mesenteroides subsp. cremoris. Res. Microbiol. 150, 189-198. doi: 10.1016/S0923-2508(99)80035-7

Cibik, R., Lepage, E., and Talliez, P. (2000). Molecular diversity of Leuconostoc mesenteroides and Leuconostoc citreum isolated from traditional french cheeses as revealed by RAPD fingerprinting, 16S rDNA sequencing and 16S rDNA fragment amplification. Syst. Appl. Microbiol. 23, 267-278. doi: 10.1016/S0723-2020(00)80014-4

Cogan, T. M., and Jordan, K. N. (1994). Metabolism of Leuconostoc bacteria. J. Dairy Sci. 77, 2704-2717. doi: 10.3168/jds.S0022-0302(94)77213-1

Conesa, A., Götz, S., García-Gómez, J. M., Terol, J., Talón, M., and Robles, M. (2005). Blast2GO: a universal tool for annotation, visualization and analysis in functional genomics research. Bioinformatics 21, 3674-3676. doi: 10.1093/bioinformatics/bti610

Contreras-Moreira, B., and Vinuesa, P. (2013). GET_HOMOLOGUES, a versatile software package for scalable and robust microbial pangenome analysis. Appl. Environ. Microbiol. 79, 7696-7701. doi: 10.1128/AEM.02411-13

Dan, T., Liu, W., Sun, Z., Lv, Q., Xu, H., Song, Y., et al. (2014). A novel multilocus sequence typing (MLST) protocol for Leuconostoc lactis isolates from traditional dairy products in China and Mongolia. BMC Microbiol. 14:150. doi: 10.1186/1471-2180-14-150

Drider, D., Bekal, S., and Prévost, H. (2004). Genetic organization and expression of citrate permease in lactic acid bacteria. Genet. Mol. Res. 3, 273-281. 
Edgar, R. C. (2010). Search and clustering orders of magnitude faster than BLAST. Bioinformatics 26, 2460-2461. doi: 10.1093/bioinformatics/btq461

Edgar, R. C. (2013). UPARSE: highly accurate OTU sequences from microbial amplicon reads. Nat. Methods 10, 996-998. doi: 10.1038/nme th. 2604

Enright, A. J., Van Dongen, S., and Ouzounis, C. A. (2002). An efficient algorithm for large-scale detection of protein families. Nucleic Acids Res. 30, 1575-1584. doi: $10.1093 /$ nar/30.7.1575

Erkus, O., de Jager, V. C., Spus, M., van Alen-Boerrigter, I. J., van Rijswijck, I. M., Hazelwood, L., et al. (2013). Multifactorial diversity sustains microbial community stability. ISME J. 7, 2126-2136. doi: 10.1038/ismej.2013.108

Farrow, J. A. E., Facklam, R. R., and Collins, M. D. (1989). Nucleic acid homologies of some vancomycin-resistant leuconostocs and description of Leuconostoc citreum sp. nov. and Leuconostoc pseudomesenteroides sp. nov. Int. J. Syst. Evol. Microbiol. 39, 279-283.

Galili, T. (2015). Dendextend: Extending R's dendrogram functionality. $\mathrm{R}$ package version 0.18.3. [Computer software]. Available online at: http://CRAN.R-project.org/package=dendextend

Garvie, E. I. (1960). The genus Leuconostoc and its nomenclature. J. Dairy Res. 27, 283-292. doi: 10.1017/S0022029900010359

Garvie, E. I. (1967). The growth factor and amino acid requirements of species of the genus Leuconostoc, including Leuconostoc paramesenteroides (sp.nov.) and Leuconostoc oenos. Microbiology 48, 439-447. doi: 10.1099/00221287-48-3-439

Garvie, E. I. (1969). Lactic dehydrogenases of strains of the genus Leuconostoc. Microbiology 58, 85-94. doi: 10.1099/00221287-58-1-85

Garvie, E. I. (1979). Proposal of neotype strains for Leuconostoc mesenteroides (Tsenkovskii) van Tieghem, Leuconostoc dextranicum (Beijerinck) Hucker and Pederson, and Leuconostoc cremoris (Knudsen and Sørensen) Garvie. Int. J. Syst. Evol. Microbiol. 29, 149-151.

Garvie, E. I. (1983). NOTES: Leuconostoc mesenteroides subsp. cremoris (Knudsen and Sørensen) comb. nov. and Leuconostoc mesenteroides subsp. dextranicum (Beijerinck) comb. nov. Int. J. Syst. Evol. Microbiol. 33, 118-119.

Garvie, E. I., Zezula, V., and Hill, V. A. (1974). Guanine plus cytosine content of the deoxyribonucleic acid of the leuconostocs and some heterofermentative lactobacilli. Int. J. Syst. Evol. Microbiol. 24, 248-251. doi: 10.1099/00207713-24-2-248

Godon, J. J., Delorme, C., Bardowski, J., Chopin, M. C., Ehrlich, S. D., and Renault, P. (1993). Gene inactivation in Lactococcus lactis: branched-chain amino acid biosynthesis. J. Bacteriol. 175, 4383-4390. doi: $10.1128 /$ jb.175.14.4383-4390.1993

Grissa, I., Vergnaud, G., and Pourcel, C. (2007). CRISPRFinder: a web tool to identify clustered regularly interspaced short palindromic repeats. Nucleic Acids Res. 35, W52-W57. doi: 10.1093/nar/gkm360

Gu, C. T., Wang, F., Li, C. Y., Liu, F., and Huo, G. C. (2012). Leuconostoc mesenteroides subsp. suionicum subsp. nov. Int. J. Syst. Evol. Microbiol. 62, 1548-1551. doi: 10.1099/ijs.0.031203-0

Gunnewijk, M. G., and Poolman, B. (2000). HPr(His approximately P)-mediated phosphorylation differently affects counterflow and proton motive force-driven uptake via the lactose transport protein of Streptococcus thermophilus. J. Biol. Chem. 275, 34080-34085. doi: 10.1074/jbc.M003513200

Hache, C., Cachon, R., Wache, Y., Belguendouz, T., Riondet, C., Deraedt, A., et al. (1999). Influence of lactose-citrate co-metabolism on the differences of growth and energetics in Leuconostoc lactis, Leuconostoc mesenteroides ssp. mesenteroides and Leuconostoc mesenteroides ssp. cremoris. Syst. Appl. Microbiol. 22, 507-513. doi: 10.1016/S0723-2020(99)80002-2

Hemme, D., and Foucaud-Scheunemann, C. (2004). Leuconostoc, characteristics, use in dairy technology and prospects in functional foods. Int. Dairy J. 14, 467-494. doi: 10.1016/j.idairyj.2003.10.005

Hugenholtz, J. (1993). Citrate metabolism in lactic acid bacteria. FEMS Microbiol. Rev. 12, 165-178. doi: 10.1111/j.1574-6976.1993.tb00017.x

Johansen, E., and Kibenich, A. (1992). Characterization of Leuconostoc isolates from commercial mixed strain mesophilic starter cultures. J. Dairy Sci. 75, 1186-1191. doi: 10.3168/jds.S0022-0302(92)77865-5

Jung, J. Y., Lee, S. H., Lee, S. H., and Jeon, C. O. (2012). Complete genome sequence of Leuconostoc mesenteroides subsp. mesenteroides strain J18, isolated from kimchi. J. Bacteriol. 194, 730-731. doi: 10.1128/JB.06498-11

Kanehisa, M., and Goto, S. (2000). KEGG: kyoto encyclopedia of genes and genomes. Nucleic Acids Res. 28, 27-30. doi: 10.1093/nar/28.1.27
Kearse, M., Moir, R., Wilson, A., Stones-Havas, S., Cheung, M., Sturrock, S., et al. (2012). Geneious basic: an integrated and extendable desktop software platform for the organization and analysis of sequence data. Bioinformatics 28 , 1647-1649. doi: 10.1093/bioinformatics/bts199

Kleppen, H. P., Nes, I. F., and Holo, H. (2012). Characterization of a Leuconostoc bacteriophage Infecting flavor producers of cheese starter cultures. Appl. Environ. Microbiol. 78, 6769-6772. doi: 10.1128/AEM.00562-12

Lin, J., Schmitt, P., and Diviès, C. (1991). Characterization of a citrate-negative mutant of Leuconostoc mesenteroides subsp. mesenteroides: metabolic and plasmidic properties. Appl. Microbiol. Biotechnol. 34, 628-631.

Lodics, T. A., and Steenson, L. R. (1990). Characterization of bacteriophages and bacteria indigenous to a mixed-strain cheese starter. J. Dairy Sci. 73, 2685-2696. doi: 10.3168/jds.S0022-0302(90)78953-9

Magni, C., de Felipe, F. L., Sesma, F., López, P., and de Mendoza, D. (1994). Citrate transport in Lactococcus lactis biovar diacetylactis: expression of the plasmid-borne citrate permease p. FEMS Microbiol. Lett. 118, 75-82. doi: 10.1111/j.1574-6968.1994.tb06806.x

Marty-Teysset, C., Posthuma, C., Lolkema, J. S., Schmitt, P., Divies, C., and Konings, W. N. (1996). Proton motive force generation by citrolactic fermentation in Leuconostoc mesenteroides. J. Bacteriol. 178, 2178-2185. doi: $10.1128 / \mathrm{jb} .178 .8 .2178-2185.1996$

Meslier, V., Loux, V., and Renault, P. (2012). Genome sequence of Leuconostoc pseudomesenteroides strain 4882, isolated from a dairy starter culture. J. Bacteriol. 194, 6637. doi: 10.1128/jb.01696-12

Monnet, C., Phalip, V., Schmitt, P., and Diviès, C. (1994). Comparison of $\alpha-$ acetolactate synthase and $\alpha$-acetolactate decarboxylase in Lactococcus spp. and Leuconostoc spp. Biotechnol. Lett. 16, 257-262. doi: 10.1007/BF00134622

Nieto-Arribas, P., Seseña, S., Poveda, J. M., Palop, L., and Cabezas, L. (2010). Genotypic and technological characterization of Leuconostoc isolates to be used as adjunct starters in Manchego cheese manufacture. Food Microbiol. 27, 85-93. doi: 10.1016/j.fm.2009.08.006

Nurk, S., Bankevich, A., Antipov, D., Gurevich, A. A., Korobeynikov, A., Lapidus, A., et al. (2013). Assembling single-cell genomes and minimetagenomes from chimeric MDA products. J. Comput. Biol. 20, 714-737. doi: $10.1089 / \mathrm{cmb} .2013 .0084$

Obst, M., Meding, E. R., Vogel, R. F., and Hammes, W. P. (1995). Two genes encoding the $\beta$-galactosidase of Lactobacillus sakei. Microbiology $141(\mathrm{Pt} 12)$, 3059-3066. doi: 10.1099/13500872-141-12-3059

Olsen, K. N., Brockmann, E., and Molin, S. (2007). Quantification of Leuconostoc populations in mixed dairy starter cultures using fluorescence in situ hybridization. J. Appl. Microbiol. 103, 855-863. doi: 10.1111/j.1365-2672.2007.03298.x

Østlie, H. M., Kraggerud, H., Longva, A. B., and Abrahamsen, R. K. (2016). Characterisation of the microflora during ripening of a Norwegian semi-hard cheese with adjunct culture of propionic acid bacteria. Int. Dairy J. 54, 43-49. doi: 10.1016/j.idairyj.2015.10.005

Overbeek, R., Olson, R., Pusch, G. D., Olsen, G. J., Davis, J. J., Disz, T., et al. (2014). The SEED and the Rapid Annotation of microbial genomes using Subsystems Technology (RAST). Nucleic Acids Res. 42, D206-D214. doi: 10.1093/nar/gkt1226

Pedersen, T. B., Kot, W. P., Hansen, L. H., Sørensen, S. J., Broadbent, J. R., Vogensen, F. K., et al. (2014a). Genome sequence of Leuconostoc mesenteroides subsp. cremoris Strain T26, isolated from mesophilic undefined cheese starter. Genome Announc. 2:e00485-14. doi: 10.1128/genomeA.00 485-14

Pedersen, T. B., Kot, W. P., Hansen, L. H., Sørensen, S. J., Broadbent, J. R., Vogensen, F. K., et al. (2014b). Genome sequences of two Leuconostoc pseudomesenteroides strains isolated from danish dairy starter cultures. Genome Announc. 2:e00484-14. doi: 10.1128/genomeA.00484-14

Pedersen, T. B., Vogensen, F. K., and Ardo, Y. (2016). Effect of heterofermentative lactic acid bacteria of DL-starters in initial ripening of semi-hard cheese. Int. Dairy J. 57, 72-79. doi: 10.1016/j.idairyj.2016.02.041

Pérez, G., Cardell, E., and Zárate, V. (2002). Random amplified polymorphic DNA analysis for differentiation of Leuconostoc mesenteroides subspecies isolated from Tenerife cheese. Lett. Appl. Microbiol. 34, 82-85. doi: 10.1046/j.1472-765x.2002.01050.x

Porcellato, D., Ostlie, H. M., Brede, M. E., Martinovic, A., and Skeie, S. B. (2013). Dynamics of starter, adjunct non-starter lactic acid bacteria and propionic acid 
bacteria in low-fat and full-fat Dutch-type cheese. Int. Dairy J. 33, 104-111. doi: 10.1016/j.idairyj.2013.01.007

Porcellato, D., and Skeie, S. B. (2016). Bacterial dynamics and functional analysis of microbial metagenomes during ripening of Dutch-type cheese. Int. Dairy J. 61, 182-188. doi: 10.1016/j.idairyj.2016.05.005

Salvador, S., and Chan, P. (2004). "Determining the number of clusters/segments in hierarchical clustering/segmentation algorithms," in Proceedings of the 16th IEEE International Conference on Tools with Artificial Intelligence (Boca Raton, FL: IEEE Computer Society).

Sánchez, J. I., Martínez, B., and Rodríguez, A. (2005). Rational selection of Leuconostoc strains for mixed starters based on the physiological biodiversity found in raw milk fermentations. Int. J. Food Microbiol. 105, 377-387. doi: 10.1016/j.ijfoodmicro.2005.04.025

Seemann, T. (2014). Prokka: rapid prokaryotic genome annotation. Bioinformatics 30, 2068-2069. doi: 10.1093/bioinformatics/btu153

Thunell, R. K. (1995). Taxonomy of the Leuconostocs. J. Dairy Sci. 78, 2514-2522. doi: 10.3168/jds.S0022-0302(95)76881-3

Vaughan, E. E., David, S., Harrington, A., Daly, C., Fitzgerald, G. F., and De Vos, W. M. (1995). Characterization of plasmid-encoded citrate permease (citP) genes from Leuconostoc species reveals high sequence conservation with the Lactococcus lactis citP gene. Appl. Environ. Microbiol. 61, 3172-3176.

Vedamuthu, E. R. (1994). The dairy Leuconostoc: use in dairy products. J. Dairy Sci. 77, 2725-2737. doi: 10.3168/jds.S0022-0302(94)77215-5

Vihavainen, E. J., and Björkroth, K. J. (2009). Diversity of Leuconostoc gasicomitatum associated with meat spoilage. Int. J. Food Microbiol. 136, 32-36. doi: 10.1016/j.ijfoodmicro.2009.09.010

Villani, F., Moschetti, G., Blaiotta, G., and Coppola, S. (1997). Characterization of strains of Leuconostoc mesenteroides by analysis of soluble whole-cell protein pattern, DNA fingerprinting and restriction of ribosomal DNA. J. Appl. Microbiol. 82, 578-588. doi: 10.1111/j.1365-2672.1997.tb03588.x

Vogensen, F. K., Karst, T., Larsen, J. J., Kringelum, B., Ellekjaer, D., and Waagner Nielsen, E. (1987). Improved direct differentiation between Leuconostoc cremoris, Streptococcus lactis ssp. diacetylactis, and Streptococcus cremoris/Streptococcus lactis on agar. Milchwissenschaft 42, 646-648.

Vongerichten, K. F., Klein, J. R., Matern, H., and Plapp, R. (1994). Cloning and nucleotide sequence analysis of pepV, a carnosinase gene from Lactobacillus delbrueckii subsp. lactis DSM 7290, and partial characterization of the enzyme. Microbiology 140, 2591-2600. doi: 10.1099/00221287-140-1 0-2591

Ward, D. M., Weller, R., and Bateson, M. M. (1990). 16S rRNA sequences reveal numerous uncultured microorganisms in a natural community. Nature 345, 63-65.

Warnes, G. R., Bolker, B., Bonebakker, L., R. G., Liaw, W. H. A., Lumley, T., Maechler, M., et al. (2015). gplots: Various R Programming Tools for Plotting Data. R package version 2.16.0. [Computer software]. Available online at: http://CRAN.R-project.org/package=gplots

Wright, E. (2015). DECIPHER: Database Enabled Code for Ideal Probe Hybridization Employing. R. package v1.16.1.

Zeller-Péronnet, V., Brockmann, E., Pavlovic, M., Timke, M., Busch, U., and Huber, I. (2013). Potential and limitations of MALDI-TOF MS for discrimination within the species Leuconostoc mesenteroides and Leuconostoc pseudomesenteroides. J. für Verbraucherschutz und Lebensmittelsicherheit 8, 205-214. doi: 10.1007/s00003-013-0826-Z

Zhang, J., Kobert, K., Flouri, T., and Stamatakis, A. (2014). PEAR: a fast and accurate Illumina Paired-End reAd mergeR. Bioinformatics 30, 614-620. doi: 10.1093/bioinformatics/btt593

Zhang, W., Liu, W., Song, Y., Xu, H., Menghe, B., Zhang, H., et al. (2015). Multilocus sequence typing of a dairy-associated Leuconostoc mesenteroides population reveals clonal structure with intragenic homologous recombination. J. Dairy Sci. 98, 2284-2293. doi: 10.3168/jds.2014-9227

Zhao, Y., Jia, X., Yang, J., Ling, Y., Zhang, Z., Yu, J., et al. (2014). PanGP: a tool for quickly analyzing bacterial pan-genome profile. Bioinformatics 30, 1297-1299. doi: 10.1093/bioinformatics/btu017

Conflict of Interest Statement: The authors declare that the research was conducted in the absence of any commercial or financial relationships that could be construed as a potential conflict of interest.

Copyright (C) 2017 Frantzen, Kot, Pedersen, Ardö, Broadbent, Neve, Hansen, Dal Bello, Østlie, Kleppen, Vogensen and Holo. This is an open-access article distributed under the terms of the Creative Commons Attribution License (CC BY). The use, distribution or reproduction in other forums is permitted, provided the original author(s) or licensor are credited and that the original publication in this journal is cited, in accordance with accepted academic practice. No use, distribution or reproduction is permitted which does not comply with these terms. 